\title{
A New Low-Cost Hybrid Switched Reluctance Motor for Adjustable-Speed Pump Applications
}

\author{
K. Y. Lu, \\ P. O. Rasmussen, \\ Institute of Energy Technology \\ S. J. Watkins, F. Blaabjerg \\ Aalborg University \\ DK-9220 Aalborg Øst, Denmark
}

\begin{abstract}
This paper presents a new low-cost, hybrid SR motor intended for use in adjustable-speed pump drive systems. This motor is a single-phase motor, driven by a unipolar converter. This motor uses both the reluctance torque and the permanent magnet interaction torque. Compared with normal single-phase SR motors, it has an increased torque density. The cogging torque is properly used in this motor for reducing the torque ripple. It is demonstrated that such a motor drive system can be a suitable candidate to advantageously compete with the existing motor drive systems for low-cost applications. Finite Element models are used to analyze and predict the motor's performance. The proposed motor drive system has been fabricated and its performance tested in the laboratory. These experimental results are also presented.
\end{abstract}

Keywords-low-cost; hybrid switched reluctance motor; adjustable-speed;

\section{INTRODUCTION}

Over the last decade, there has been growing interest in new adjustable-speed SR and PM drives to replace the conventional IM drives for applications like pumps. In these applications, the cost constraint has dictated the need for lowcost motors and drive systems. For the pumps to be used indoors, the acoustic noise and efficiency are considered to be important factors.

To reduce the cost of a drive system, one of the options is to use a drive system with a reduced number of power electronic switches. Less power devices would also simplify the control strategy and the drive circuitry, which increases the robustness of the drive system.

Often, bipolar converters require more power switches than unipolar converters. The cost of a drive system could be reduced by substituting the bipolar converters with unipolar converters controlling the same type of motors. For example, in [1] and [2], two low-cost unipolar drive systems were introduced for controlling a 3-phase BLDC motor. Another possible method to reduce the number of power switches and thus the drive system's cost is to reduce the number of phases of the motor, without sacrificing motor performance. The simplest motor topology would be a single-phase motor, controlled by a unipolar converter, and these are of great interest for low-cost applications.

In [3], Muller presented a single-phase motor with a PM rotor and variable air gap length for low-cost applications. This motor is simple, cheap and is able to self-start. However it needs bipolar excitation and its torque will fall to zero twice in one rotational period. The torque ripple is high. A similar design was reported in [4], where the author used a notched rotor to solve the self-starting problem. The single-phase PM motor may also be constructed in a transverse flux manner, as presented in [5], [6]. This kind of motors may only be suitable for the loads like fans, due to the high torque ripple problem. A PM motor naturally requires bipolar currents and even for a single-phase PM motor, it may need four switches. If unipolar converters are used, the PM motor may only be able to produce half of the torque due to half-wave operation. To achieve the same output torque as controlled by bipolar converters within the same motor size, the unipolar current needs to be increased, which results in increased copper loss and reduced motor efficiency. The PM motor may also use a bifilar winding to accommodate the unipolar converter. But a bifilar winding requires much more slot area. The copper loss of a bifilar winding will be high and it may be difficult to improve the efficiency. In short, PM motors controlled by unipolar converters would result in poor utilization of the motor.

Unlike PM motors, SR motors naturally suit unipolar excitations. In [7], Compter introduced a low-cost drive system using a single-phase SR motor with two parking magnets. Similar motor designs could be found in [8], [9], where only one parking magnet is used. Besides using the parking magnets, controlled saturation may be used to solve the self-starting problem of a single-phase SR motor, like the motors introduced in [10] and [11]. The rotors of these motors have only two poles. It may be an advantageous to design the motor with more rotor poles to increase its torque density, like the motor introduced in [12]. All these proposed single-phase SR motors suffer from a high torque ripple problem. There is no output torque during half of one electrical period of these single-phase SR motors. The Cyrano motor, presented in [13], uses the cogging torque as positive output torque while the reluctance torque is zero by placing the parking magnets in the middle of two adjacent reluctance poles. To achieve a high positive cogging torque, thick magnets with high remanence flux densities are needed. These kinds of magnets are expensive and may not be suitable for low-cost applications.

In this paper, a new single-phase hybrid switched reluctance (HSR) motor is presented. Like the Cyrano motor, this motor uses both the reluctance torque and the permanent magnet interaction torque. The cogging torque is properly used to reduce the torque ripple. Unlike the Cyrano motor, this motor uses cheap ferrite magnets assembled in a flux 
concentration manner to achieve a high positive cogging torque, and offers more flexibility in shaping the cogging torque characteristic. The rotor of this motor is also specially designed to reduce the hydraulic loss. Finite Element models are used to analyze and predict the motor's performance and the results are presented. This motor is controlled by a twoswitch asymmetrical half-bridge converter. The experimental results for the prototype motor drive system are also given.

The topology and working principle of the proposed HSR motor are presented in section $\Pi$. The measured back EMF, flux-linkage profiles, cogging torque and interaction torque of the prototype motor are compared with the calculated results and presented in section III . The measured steady-state performance of the HSR motor drive system using a hysteresis brake as the load is given in section IV.

\section{THE PROPOSED SINGLE-PHASE HSR MOTOR}

The proposed single-phase, HSR motor is shown in Fig. 1. Some of the main dimensions and specifications of the motor are given in Table 1.

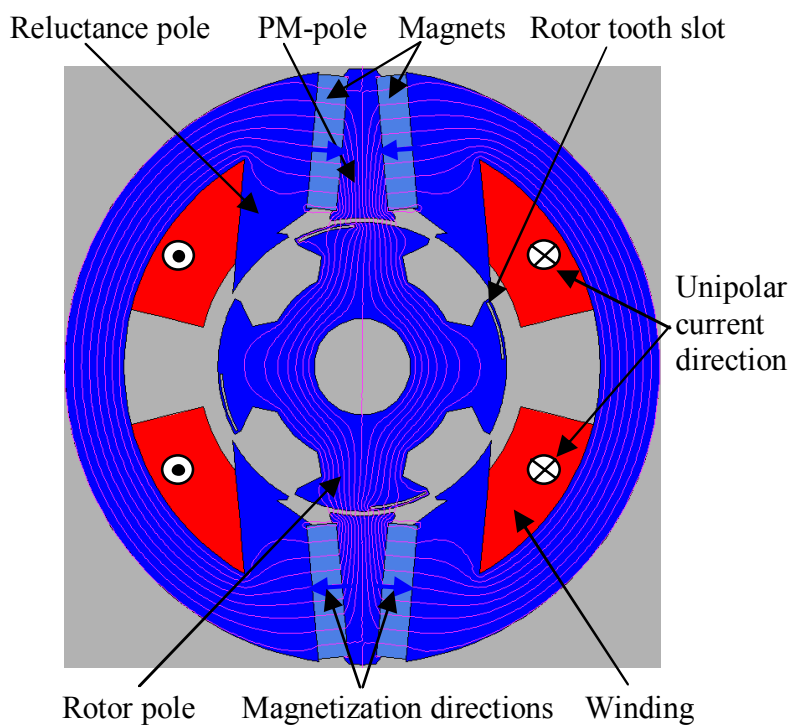

Fig. 1 Basic structure of the proposed single-phase hybrid switched reluctance motor

Table 1 main dimensions and specifications of the prototype

\begin{tabular}{|l|l|}
\hline Rated power & $30($ Watts $)$ \\
\hline Rated speed & $3000(\mathrm{RPM})$ \\
\hline Outer diameter & $80(\mathrm{~mm})$ \\
\hline Stack length & $25(\mathrm{~mm})$ \\
\hline $\begin{array}{l}\text { Rectangular ferrite permanent magnets } \\
\text { (HxWxL) }\end{array}$ & $4 \times 18 \times 40(\mathrm{~mm})$ \\
\hline Remanence of the magnets & $0.39(\mathrm{~T})$ \\
\hline Coercivity of the magnets & $250(\mathrm{KA} / \mathrm{m})$ \\
\hline
\end{tabular}

This motor has four reluctance poles and two PM-poles. There are four rectangular permanent magnets assembled in a flux concentration manner. The rotor pole has a small slot close to its surface, which functions like a stepped rotor pole providing the self-starting capability. The motor is designed to rotate in only the anticlockwise direction as viewed in Fig. 1.
The working principle of this motor could be interpreted as follows. When the rotor is in a position where the non-slotted parts of the rotor poles are aligned with the PM-poles, if a demagnetisation current, as shown in Fig. 1, is provided, the rotor will be pulled to the position aligned with the reluctance poles by a positive reluctance torque and a positive PM interaction torque. During this period, the cogging torque is negative. The current should be zero when the rotor has reached the position aligned with the reluctance poles. A positive cogging torque will then continue to pull the rotor poles to the position aligned with the PM-poles. Repeating this procedure, a steady state operation can be achieved. Fig. 2 shows an example of the instantaneous cogging torque and the instantaneous total torque for a fixed DC current for one electrical period. The results are obtained from a 2D FE model. The position 0 degrees in Fig. 2 is the position shown in Fig. 1, where the centre line of the whole rotor pole is aligned with the centre line of the stator PM-pole. It can be observed from Fig. 2 that, the rotor will settle at a position near point A before starting. Positive torque will appear if the winding current is increased and the motor is able to self-start. In steady state operations, the current should be flowing between rotor angular positions $\mathrm{B}$ and $\mathrm{C}$. After the rotor has passed position $\mathrm{C}$, the current should be zero and the cogging torque will provide positive motoring torque.

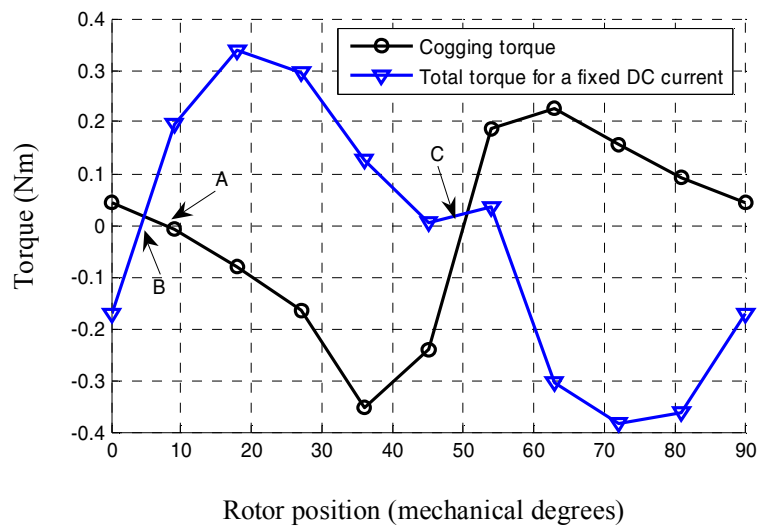

Fig. 2 The cogging torque and the total torque for a fixed DC current of the single-phase HSR motor obtained from 2D FEM

Like the Cyrano motor [13], by placing the PM-pole in the middle of two adjacent reluctance poles, the torque density of this motor could be increased compared to conventional single-phase SR motors. This is demonstrated in Fig. 3.

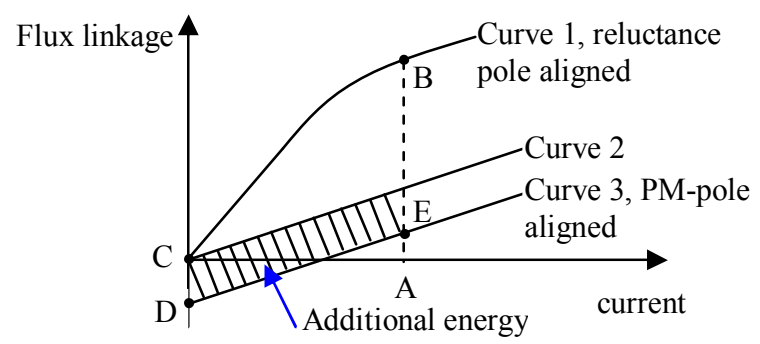

Fig. 3 Demonstration of how the PM flux linkage could be used to increase the total torque 
For a normal SR motor, the average torque for a DC current is determined by the area enclosed by curve 1 , curve 2 , and line AB. If curve 2 could be moved along the negative flux linkage axis, like curve 3 , the total enclosed area for the same current will be increased. The flux produced by the permanent magnets placed in the middle of the reluctance poles can be used to move the flux-linkage curve in such a manner as to increase the motor's torque density [13]. This increase is due to the additional PM interaction torque component.

Unlike the Cyrano motor, by using the flux concentration structure, as illustrated in Fig. 4, cheap ferrite magnets can produce a reasonably high air gap flux density, and consequently, high positive cogging torque, which is the motoring torque when the current is zero. The flux concentration structure also offers more flexibility in shaping the cogging torque characteristic, e.g., by changing the width of the PM-pole arc, using nonuniform air gap under the PMpole, or using controlled saturation [10] for the PM-pole. Fig. 5 shows two different static torque characteristics for PM-pole arcs of 28 degrees and 35 degrees. It is demonstrated in Fig. 5 that by reducing the PM-pole arc by $20 \%$, the peak cogging torque value could be increased by about $35 \%$.

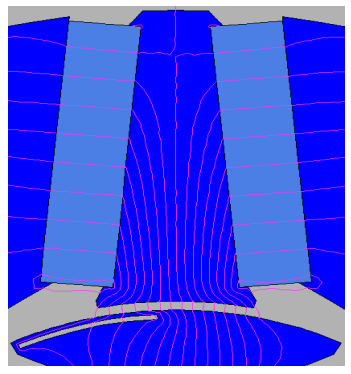

Fig. 4 Illustration of the principle of flux concentration configuration

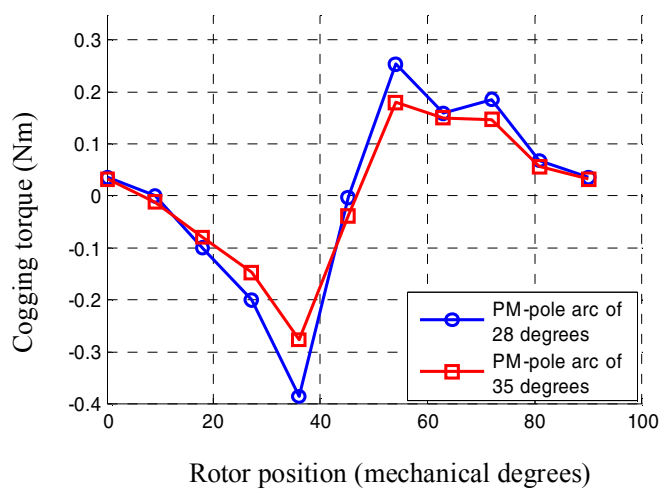

Fig. 5 Different cogging torque characteristics for different PM-pole arcs.

It should be pointed out that the cogging torque has no contribution to the average torque. The cogging torque is negative in the region where the reluctance torque and the PM interaction torque are positive. The cogging torque is used to move some of the positive torque produced by the winding current to the region where the current is zero. Compared to a conventional single-phase SR motor, whose output torque is zero when the phase current if off, the torque ripple of this HSR motor is greatly reduced. The ideal cogging torque waveform should be trapezoidal, whose average positive cogging torque equals the rated torque.

The two key features of the HSR motor in using cheap ferrite magnets, and having flexibility in shaping the cogging torque, advantageously compete with the existing Cyrano motor.

When the motor is required to operate at a speed lower than the rated speed, less torque is needed if the load is a pump. A small winding current may exist in the region where the cogging torque is positive. This current would produce negative reluctance torque, and a less total torque in that region may be obtained to meet the new torque requirement.

A prototype of the proposed HSR motor has been manufactured. The stator and the rotor of the prototype are shown in Fig. 6 7. The rotor pole of the prototype is wider than the stator pole and has a $3 \mathrm{~mm}$ deep slot. When the motor is used as a pump motor, the rotor will be sitting in the water. By having the slot inside the rotor, which functions like a 'step', the rotor surface is smooth and the hydraulic loss is reduced. The empty areas between the rotor poles are filled with special concrete, for reducing the hydraulic loss when the rotor is rotating in the water.

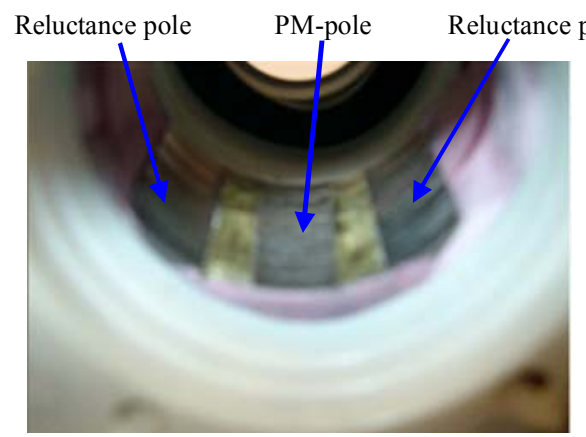

Fig. 6 A picture of the stator of the prototype HSR motor

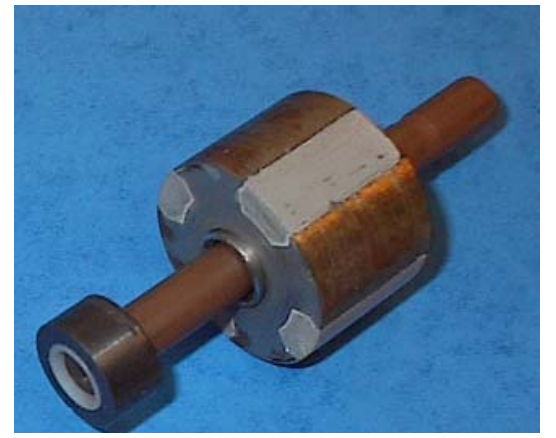

Fig. 7 A picture of the rotor of the prototype HSR motor

For this prototype, there is a non-magnetic, but conductive can placed in the air gap, which is used to prevent the water from entering the stator assembly. 


\section{STATIC MEASUREMENT RESULTS}

The test bench used to measure the prototype motor's back EMF, flux-linkage profiles, cogging torque and interaction torque at different rotor positions, is shown in Fig. 8.

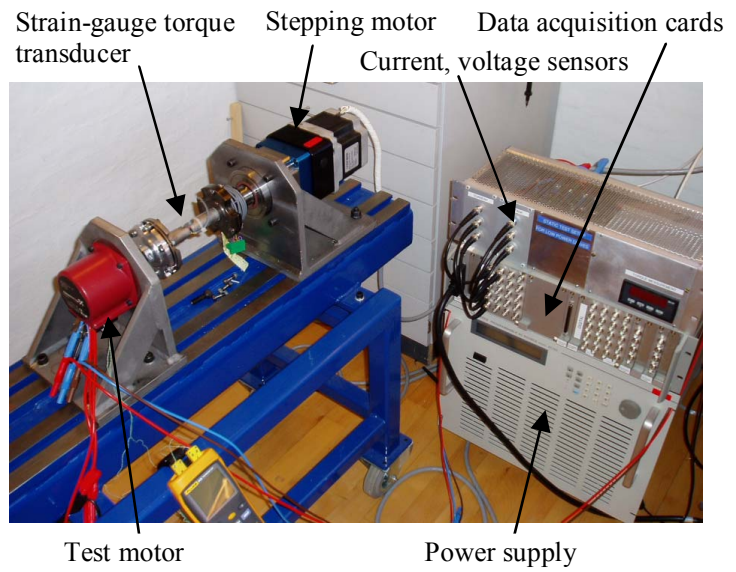

Fig. 8 Static test bench

The stepping motor can rotate the test motor to a desired position and lock it. The power supply can provide AC, DC and $\mathrm{AC}+\mathrm{DC}$ energization voltages to the test motor for static torque and flux-linkage measurements. The measured torque, current and voltage will be transferred to the computer via the data acquisition cards.

The measured and calculated back EMF waveforms are shown in Fig. 9. The flux-linkage profiles are shown in Fig. 10, and the cogging torque waveforms are shown in Fig. 11. The measured interaction torque is shown in Fig. 12 for a fixed DC current of $1.38[\mathrm{~A}]$. The interaction torque is found by subtracting the measured cogging torque from the total torque with DC current energization. All the calculated results are obtained from a 3D FE model.

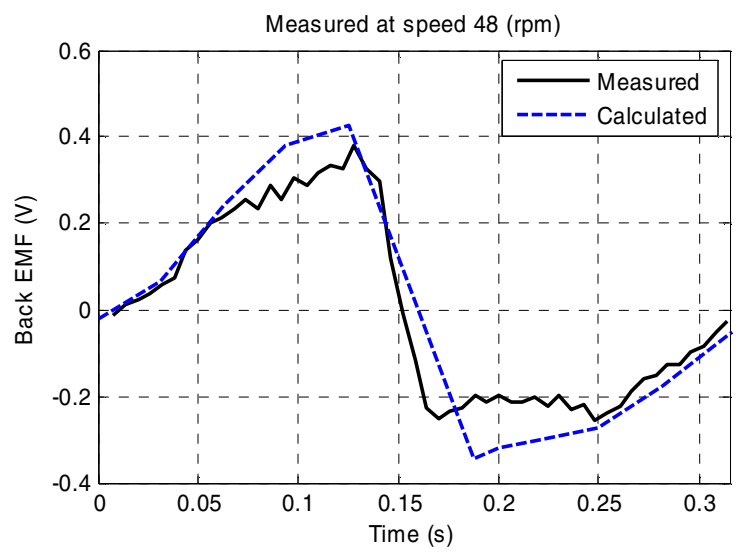

Fig. 9 Comparison of the measured and calculated back EMF waveforms at a speed of 48 (rpm).

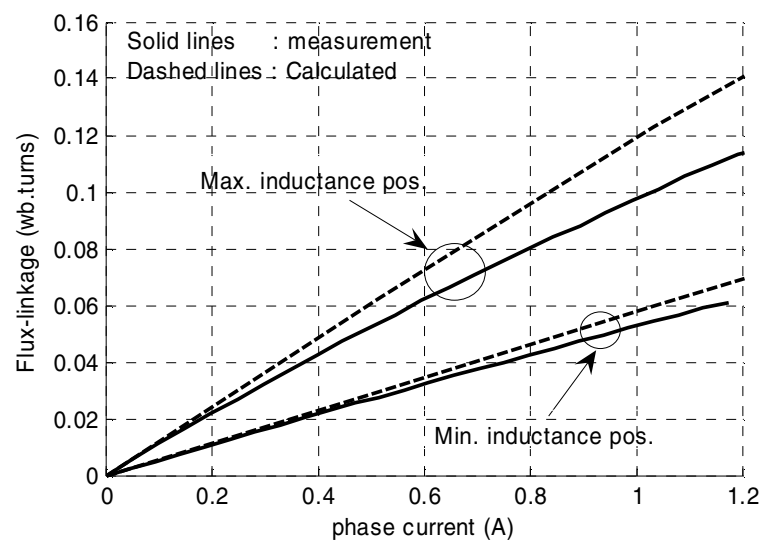

Fig.10 Comparison of the measured and calculated flux linkage profiles at the min. and max. inductances' positions.

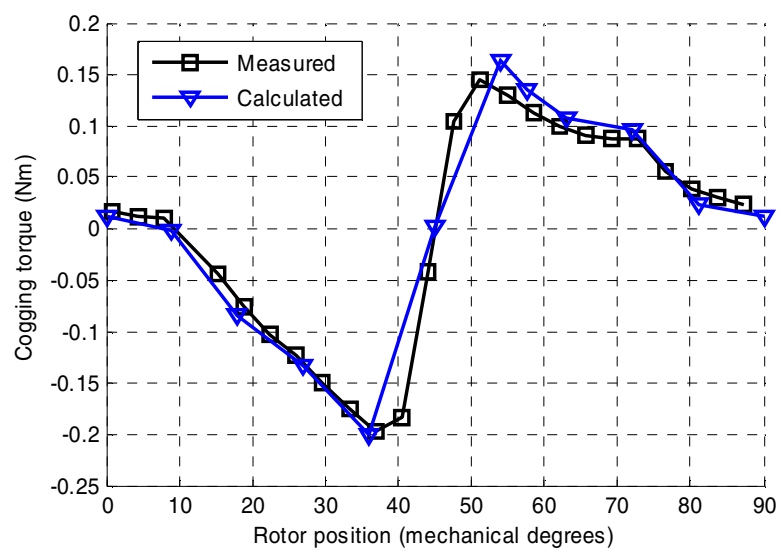

Fig.11 Comparison of the measured and calculated cogging torque waveforms of the prototype HSR motor.

Interaction torque for a fixed DC current of $1.38[\mathrm{~A}]$

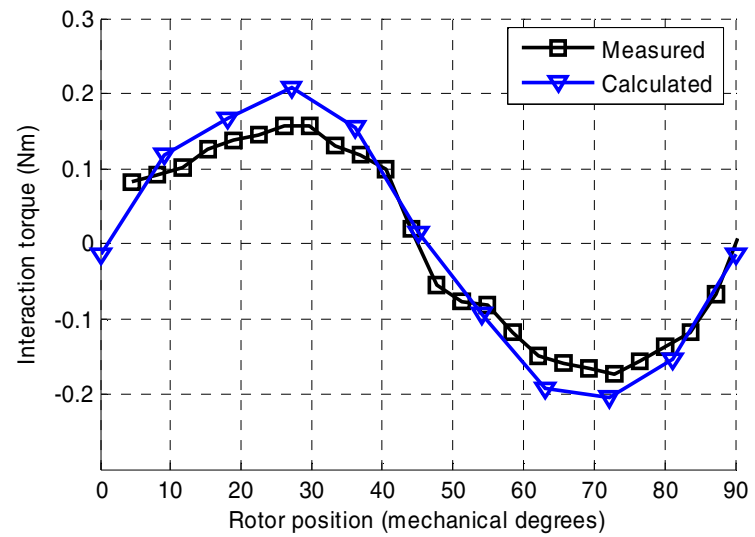

Fig.12 Comparison of the measured and calculated interaction torque, which is the total torque for a fixed DC current subtracted by the measured cogging torque 
The shapes of the calculated and measured back EMF waveforms look similar but the measured peak-to-peak value is about $30 \%$ lower than the calculated value. The measured minimum and maximum inductances are lower than the expected values, by $10 \%$ and $20 \%$ respectively. These errors may be due to wrong air gap lengths under the PM-poles and the reluctance poles.

Since the torque amplitude is small, the measurement accuracy is affected by the frictional torque, the misalignment of the shafts of the torque transducer, the coupling, and the test motor, which may introduce a DC torque offset into the measured torque. This DC torque offset was found by averaging the cogging for 90 mechanical degrees and was removed.

Using the measured instantaneous interaction torque, the average torque produced by the motor can be calculated. It should be noted that the cogging torque has no contribution to the average torque. The average torque may also be calculated using the measured minimum and maximum inductances and the back EMF. Referring to Fig. 3, the average interaction torque equals

$$
T_{\text {ave }}=4 \cdot \frac{\text { Area } B C D E}{2 \pi}
$$

where 4 is the number of rotor poles, which is also the number of torque periods per 360 mechanical degrees. Assuming linear minimum and maximum inductance profiles, it can be approximated to

$$
T_{\text {ave }}=\frac{2}{\pi}\left[\frac{1}{2} I_{a}{ }^{2}\left(L_{\max }-L_{\min }\right)+I_{a} \cdot \Delta \lambda_{p m}\right]
$$

where $I_{a}$ is the DC phase current. $L_{\max }$ and $L_{\min }$ are the maximum and minimum inductances. $\Delta \lambda_{p m}$ is the change of the PM flux-linkage from minimum inductance position to maximum inductance position.

The measured maximum and minimum inductances and $\Delta \lambda_{p m}$ are listed in table 2 . The calculated values are also included for comparison.

Table 2 Measured and calculated max. and min. inductances and the change of the PM flux linkages

\begin{tabular}{|l|c|c|}
\hline & Measured & Calculated \\
\hline Max. inductance (mH) & 97.5 & 120.8 \\
\hline Min. inductance (mH) & 52.0 & 57.5 \\
\hline $\begin{array}{l}\text { Change of PM flux linkage from min. } \\
\begin{array}{l}\text { inductance position to max. inductance } \\
\text { position (mWb.turns) }\end{array}\end{array}$ & 29.0 & 41.3 \\
\hline
\end{tabular}

The average torque vs. current profile, calculated using (2) and the measured parameters, is shown in Fig. 13. The current has a square waveform with constant amplitude between rotor angular positions 0 and 45 degrees. The average torque calculated by averaging the positive torque part of measured instantaneous interaction torque waveform is also shown in Fig. 13 for comparison. These two curves agree with each other very well, which indicates reliable torque and inductance measurements.
The measured average torque is about 30\% lower than the expected value for the same winding current. This is due to the reduction in the minimum, maximum inductances, and $\Delta \lambda_{p m}$ To achieve the rated torque, the winding current has to be increased by $30 \%$ and the copper loss would be $70 \%$ more than the designed value.

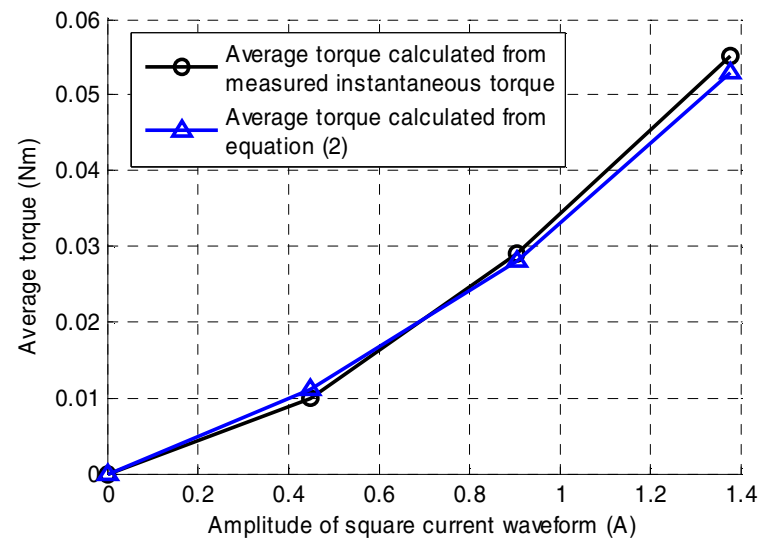

Fig. 13 Average torque vs. amplitude of square current waveform with constant amplitude between rotor angular positions 0 and 45 degrees

\section{STEADY-STATE MEASUREMENT RESULTS}

The steady-state performance of the prototype has been tested using a hysteresis brake as the load.

The converter controlling the prototype motor is an asymmetrical half-bridge converter, using two low-cost MOSFET switches (IRF840). The measured motor voltage and current waveforms controlled by this converter at 2500 (rpm), free-shaft, are shown in Fig. 14
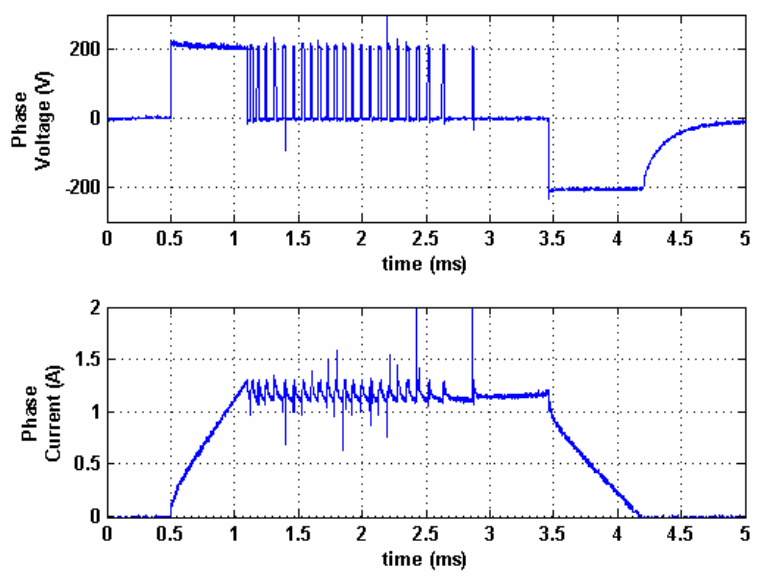

Fig. 14 Measured voltage and current waveforms at $2500 \mathrm{rpm}$, free-shaft

The equipment used for steady-state performance measurements are listed in Table 3 . The input power to the drive system, motor's input power, shaft torque are measured at different steady-state speeds. Some of the measured results are shown in Fig. 15 17. 
Table 3 A list of the equipment used for steady-state performance measurements

\begin{tabular}{|l|l|}
\hline Motor Controller & asymmetrical half-bridge converter \\
\hline Torque transducer & $\begin{array}{l}\text { Optical rotary torque transducer } \\
\text { (Full-scale torque 1 Nm) } \\
\text { (bandwidth 50KHz) }\end{array}$ \\
\hline Load & ZF hysteresis brake \\
\hline Data acquisition & Brüel \& Kjær PULSE \\
\hline
\end{tabular}

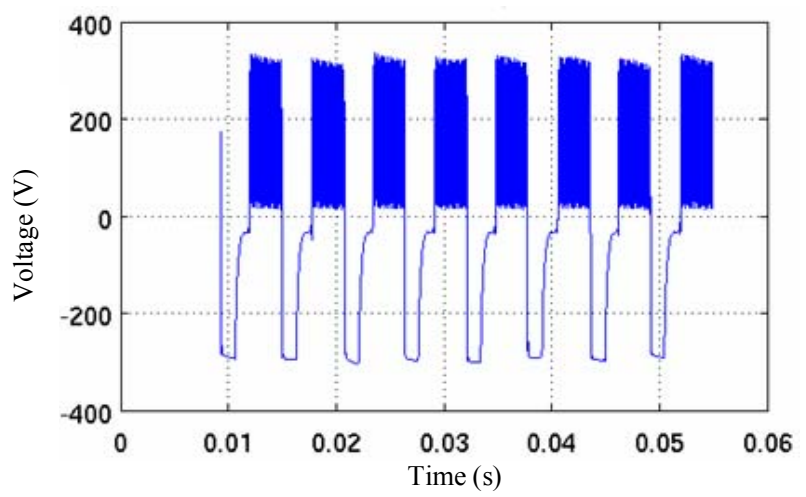

Fig. 15 Measured motor voltage at speed 2600 (rpm)

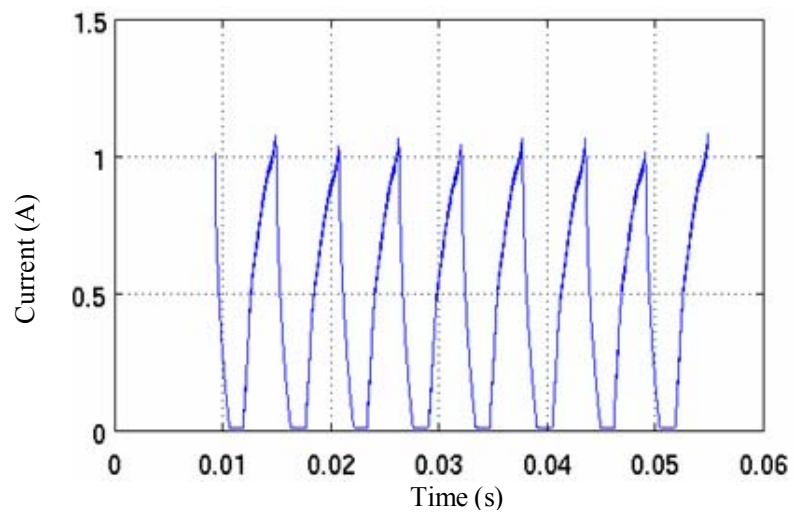

Fig. 16 Measured motor current at speed 2600 (rpm)

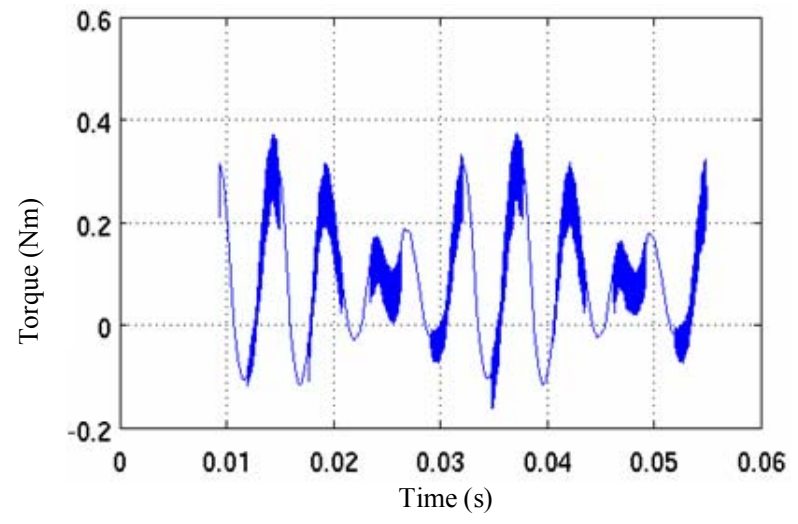

Fig. 17 Measured motor instantaneous torque at speed 2600 (rpm)

It could be observed that the measured voltage and current waveforms have a clear period of about 6 milliseconds, but the period of the measured torque waveform does not have a clear correspondence relationship to the current or voltage waveforms. The instantaneous torque produced by the motor is affected by the friction and mechanical oscillation.

The whole drive system's efficiency at the rated speed is $70 \%$. The major loss was found to be the iron loss in the can, which is extremely high and was estimated to be as much as 20 watts under certain conditions. Therefore a non-magnetic and no-conductive can is necessary for this motor to be used in the pump drive system, which will effectively increase the drive system's efficiency.

Though attempts have been made to reduce the torque ripple, this prototype motor still appears to be noisy. To use this motor for indoor pumps, future work on noise analysis and reduction will be required.

\section{CONCLUSIONS}

In this paper, a new single-phase hybrid SR motor is proposed for low-cost pump applications. This motor has higher torque density than conventional single-phase SR motors by properly using PM flux, in a similar manner to the Cyrano motor. It uses cheap ferrite magnets arranged in a flux concentration manner. The rotor has a special design for reducing the hydraulic loss associated with wet-running. The proposed motor is a suitable candidate to compete commercially with existing motors for low-cost pump applications.

\section{REFERENCES}

[1] R. Krishnan, S. Lee, 'PM brushless DC motor drive with a new powerconverter topology', IEEE Transactions on Industry Applications, Volume: 33, Issue: 4, July-Aug. 1997, Pages:973 - 982

[2] R. Krishnan, 'A novel single-switch-per-phase converter topology for four-quadrant PM brushless DC motor drive', IEEE Transactions on Industry Applications, Volume: 33 , Issue: 5, Sept.-Oct. 1997, Pages: 1154 - 1161

[3] Rolf Muller, 'Collector-less DC motor', US Patent, No. 3,873,897, Mar. 1975

[4] C. Koechli, Y. Perriard, M. Jufer, 'One phase brushless DC motor analysis', Proceeding of International Conference on Electrical Machines, 1998, Pages: 639-644

[5] Alex Horng, 'Non-brush DC motor with an improved stator', US Patent, No. 4,987,331, Jan. 1991

[6] Alex Horng, 'Non-brush DC motor with new improved stator', US Patent, No. 5,093,599, Mar. 1992

[7] Johan C. Compter, 'Single-phase reluctance motor', US Patent, No 4,616,165, Oct. 1986

[8] Gary E. Horst, 'Hybrid single-phase variable reluctance motor', US Patent, No. 5,122,697, Jun. 1992

[9] Gary E. Horst, 'Shifted pole single phase variable reluctance motor', US Patent, No. 5,294,856, Mar. 1994

[10] Peter Lurkens, 'Single-phase reluctance motor adapted to start in a desired direction of rotation', US Patent, No. 5,428,257, Jun. 1995

[11] T. Higuchi,; J.O. Fiedler, R.W. De Doncker, 'On the design of a singlephase switched reluctance motor', IEEE International Conference on Electric Machines and Drives, 2003, Volume: 1 , 1-4 June 2003 , Pages:561 - 567

[12] John M. Stephenson , 'Switched reluctance motors', US Patent, No 5,548,173, Aug. 1996

[13] V. Torok, K. Loreth, 'The world's simplest motor for variable speed control? The Cyrano motor, a PM-biased SR-motor of high torque density', the fifth European conference on Power Electronics and Applications, 13-16 Sep 1993, Pages:44 - 45 vol.6 